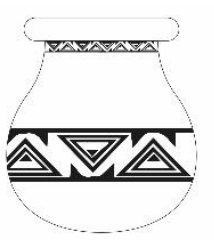

\title{
A DÍVIDA DE POPPER PARA COM KANT: OS DOIS \\ PROBLEMAS FUNDAMENTAIS DA TEORIA DO \\ CONHECIMENTO
}

Paulo Uiris da Silva Gomes ${ }^{1}$

Resumo: Este trabalho tem como objetivo refletir sobre os dois problemas fundamentais da teoria do conhecimento: o problema da demarcação científica, ou problema de Kant; e o problema da indução, ou problema de Hume. O primeiro refere-se a questão acerca do critério da demarcação, isto é, que critério devemos usar para distinguir enunciados das ciências empíricas de afirmações metafísicas e pseudocientíficas. Popper afirma que Kant foi o primeiro a formular tal problema, e com ele, a demarcação científica tornou-se o problema central da teoria do conhecimento. Discutiremos a solução de Kant e de Popper para essa questão. O segundo problema fundamental da teoria do conhecimento é o problema da indução, que se refere a questão a respeito da validade ou justificação das inferências indutivas nas ciências empíricas. Popper atribui a Hume a autoria dessa indagação. Discutiremos a abordagem de Hume sobre o tema e a solução de Kant e Popper para o problema da indução.

Palavras-Chaves: Popper; Kant; Ciência; Demarcação; Indução.

\footnotetext{
${ }^{1}$ Graduado em Filosofia e Mestrando em Filosofia pela Universidade Federal do Pará (UFPA), bolsista CAPES.
} 


\section{Introdução}

Neste trabalho analisaremos os dois problemas fundamentais da teoria do conhecimento segundo Popper: o problema da demarcação - denominado por Popper como problema de Kant - e o problema da indução - denominado também como problema de Hume. Analisando-os à luz de Popper e Kant.

É importante esclarecer que, ainda que nesse trabalho, a princípio, tratemos de Popper e Kant, nossa abordagem tem como foco o ponto de vista de Popper, e por isso, de modo geral, o Kant tratado nessa obra é o Kant popperiano, que emerge à luz da leitura de Popper.

\section{Relação entre Popper e Kant}

Popper reconhece, em diversas passagens de suas obras, o débito intelectual que tem com a filosofia kantiana. Em sua Autobiografia Intelectual (POPPER, 1990, p. 18) declara que desde a sua juventude se interessava pelos problemas kantianos e os considerava, não como pseudoproblemas ou problemas de linguagem, mas como problemas reais, e, ainda que na época não tenha compreendido muito bem a Crítica da razão pura, lia-a com certo fascínio. O primeiro livro que escreveu, intitulado Os dois problemas fundamentais da teoria do conhecimento, é, em parte, uma exposição e comentário crítico da teoria do conhecimento kantiana. Com efeito, os dois problemas fundamentais da teoria do conhecimento de Popper, são identificados por ele como os mesmos problemas centrais da primeira Crítica, a saber, o problema da indução e o problema da demarcação. Além disso, Popper afirma que sua filosofia é uma combinação de suas ideias com as de Kant (POPPER, 1990, p. 59). Ele concebe Kant como precursor de seu racionalismo-crítico (2008), seu aliado contra o positivismo (2013) e o empirismo puro (2008). Julga-se como um kantiano não-ortodoxo em filosofia da ciência e como um kantiano em ética. E, por fim, sustenta que seu racionalismo e empirismo críticos são apenas um toque final na filosofia crítica kantiana (2008).

Popper interpreta a Crítica da razão pura como um tratado de epistemologia, e sua ideia fundamental é que "as teorias científicas são criações humanas, e nós tentamos impô-las à natureza: 'nosso intelecto não deriva suas leis da natureza, mas impõe leis à natureza"' (POPPER, 2008, p. 59). Nessa leitura, o objetivo central da crítica é solucionar os dois problemas fundamentais da teoria do conhecimento (POPPER, 2013, p. 20), o problema da demarcação científica, tratado na dialética transcendental, e o problema da indução, abordado na analítica transcendental. 


\section{O problema da demarcação: o problema de Kant}

Popper, em sua obra Lógica da pesquisa científica, apresenta o problema da demarcação como o "problema de estabelecer um critério que nos habilite a distinguir entre as ciências empíricas, de uma parte, e a Matemática e a Lógica, bem como os sistemas 'metafísicos', de outra" (POPPER, 2013, p. 33).

Popper afirma que o primeiro a formular o problema da demarcação foi Kant. Nas palavras do filósofo austríaco: "Kant foi certamente o primeiro a ter de fato colocado a demarcação entre ciência e metafísica no centro de suas considerações filosóficas" (POPPER, 2013, p. 459), e com Kant, a demarcação - ou a questão kantiana sobre os limites do conhecimento científico - tornou-se o problema central em torno do qual giram todas as outras questões da teoria do conhecimento, inclusive o problema da indução. Sendo assim, a abordagem de Kant a respeito desse problema é tão significativa que Popper denomina o problema da demarcação como o "problema de Kant".

Kant afirma, no prefácio à segunda edição da Crítica da razão pura (B VII), que um dos problemas centrais do livro é buscar uma resposta a questão: "a elaboração dos conhecimentos pertencentes ao ofício da razão estão ou não no caminho seguro de uma ciência?" Em outras palavras, a metafísica pertence a ciência? Dessa questão podemos derivar outras: Quais os limites do conhecimento científico? Que critério demarca a ciência empírica? Ciência e metafísica são distintas?

Na leitura de Popper, quando Kant (2013, B 20) questiona "como é possível a matemática pura? Como é possível a ciência pura da natureza?", ele está tratando do problema da demarcação. Nesse questionamento Kant busca definir os limites do conhecimento e delimitar a fronteira entre ciência e metafísica.

É na Dialética transcendental que Kant visa solucionar o problema da demarcação, limitando o uso científico das "ideias da razão pura" ao domínio da experiência possível que é considerada como a pedra de toque da verdade das regras.

Kant soluciona o problema da demarcação científica definindo a ciência como juízos sintéticos a priori. Nesse âmbito, os enunciados científicos são sintéticos, pois devem acrescentar predicados novos ao conceito do sujeito, e são também a priori porque devem ser necessários e universais. Diz o filósofo: "a ciência da natureza contém em si mesma juízos sintéticos a priori como princípio" (Kant, 2013, B 17). Ou seja, o juízo que fundamenta a ciência e o conhecimento, une a universalidade e necessidade do a priori com a fecundidade e amplitude do sintético. No mesmo texto, Kant também argumenta que deve ser possível 
estabelecer os "exatos e seguros limites" (B 22) de nossa razão.

Popper compreende que na argumentação de Kant o problema central é definir os limites do conhecimento e demarcar a ciência. E concorda parcialmente com a solução kantiana para o problema da demarcação científica. Para Popper, os enunciados científicos são, de fato, sintéticos, como defende Kant, contudo sua validade não é dada a priori, e sim $a$ posteriori, após serem postas à prova pela experiência. O que é a priori é a criação de nossas conjecturas, ou seja, elas são geneticamente a priori.

Além disso, Popper (2013, p. 37) elege três requisitos que qualquer sistema teórico deve satisfazer para pertencer à ciência empírica, a saber: o sistema teórico deve ser (a) sintético, isto é, representar um mundo possível; (b) falseável, ou seja, precisa satisfazer o critério da demarcação, sendo não metafísico e representando o mundo da experiência possível; e (c) deve ser o único representativo do mundo da experiência, sendo assim, deve ser diferente de outros sistemas teóricos, representando um progresso científico.

\section{O problema da indução: o problema de Hume}

Primeiramente, na obra Os dois problemas fundamentais da teoria do conhecimento (POPPER, 2013, p. 20), Popper apresenta o problema da indução como sendo um dos problemas fundamentais da epistemologia que Kant se ocupa na Crítica da razão pura, mais especificamente na seção da analítica transcendental.

Todavia, posteriormente, na Lógica da pesquisa científica, Popper, diferente do que havia declarado em seu manuscrito de 1933, considera como problema de Kant apenas o problema da demarcação científica, o problema da indução é atribuído a autoria a Hume. Pois Hume, afirma Popper, já havia deixado claro que da lógica indutiva surgem incoerências (POPPER, 2013, p. 28). Tal mudança decorre da influência que Popper sofreu pela leitura de Kant, Popper quis acompanhar Kant na identificação do problema da indução como o 'problema de Hume', embora não concorde com Kant quanto a natureza desse problema.

Contudo, é Popper quem denomina o problema da indução como o 'problema de Hume', não Kant. Para Kant, como argumenta nos Prolegômenos, o 'problema de Hume' refere-se ao problema da causalidade (KANT, 1988, p. 14) e não da indução.

Popper, assim como Kant, concebe que haja em Hume um problema acerca da causalidade. Todavia, entende que na base desse problema está outro mais fundamental: o problema da indução. Para o filósofo austríaco (Popper, 1975, p. 89), o que Kant havia chamado de "problema de Hume", isto é, o problema da causação, parte-se em dois outros 


\section{REVISTA APOENA - Per. dos Dis. de Fil. da UFPA}

Belém, 2019, V. 1, N.1.

problemas, a saber, o problema causal e o problema da indução.

Em que consiste, exatamente, o problema da indução? Consiste na questão de saber se as inferências indutivas se justificam e em que condições elas poderiam ser justificadas. Dito de outro modo (POPPER, 2013, p. 27), o problema da indução é a indagação acerca da validade ou verdade de enunciados universais que encontrem base na experiência, tais como as hipóteses e os sistemas teóricos das ciências empíricas. A indução é problemática porque observamos apenas eventos singulares, e sempre um número limitado destes, sendo assim, pode-se confirmar imediatamente pela observação somente proposições particulares. Entretanto, nas ciências empíricas existem proposições universais (gerais), isto é, proposições que fazem afirmações sobre um número ilimitado de eventos: qual seria, então, a justificativa para inferir enunciados universais de enunciados particulares? E quão válidos seriam tais enunciados universais?

De acordo com a leitura de Popper, Hume levanta dois problemas a respeito da indução, a saber: um problema lógico e um problema psicológico. O problema lógico seria o seguinte (POPPER, 1975, p. 15): há justificação em tirar conclusões, partindo de exemplos que temos experiências, para outros exemplos dos quais não temos experiência? A resposta de Hume seria: não, por maior que seja o número de repetições dos eventos que já temos experiência. Por sua vez, o problema psicológico é: por que, então, esperamos que eventos dos quais não temos experiência aconteçam do mesmo modo que aqueles que temos experiência? Por exemplo, por que, então, esperamos que amanhã nasça o sol assim como nasceu em todos os dias passados? Por que confiamos tanto nessas expectativas? Hume responde da seguinte maneira: Por causa do costume, do hábito. Porque somos condicionados pelas repetições e pelas associações de ideias.

Kant responde ao problema da indução diferentemente de Hume, para ele, Hume não considerou a possibilidade de haver um princípio de causalidade (ou de indução) que fosse válido a priori. A posição de Kant, para salvar a racionalidade humana do irracionalismo que Hume a submetera, é a de admitir a existência de enunciados sintéticos válidos a priori. Sendo assim, o princípio da causalidade, a aritmética, a geometria e parte da física newtoniana seriam considerados como sintéticos a priori.

Mas como é que a verdade do princípio de causalidade, por exemplo, poderia ser estabelecida a priori? Para solucionar o problema da possibilidade de juízos sintéticos a priori, Kant opera a sua notória "revolução copernicana" na teoria do conhecimento. Isto é, Kant percebeu que as teorias não têm origem na observação, nos sentidos, na experiência, mas sim que há uma participação ativa do intelecto na produção de nossas conjecturas. As leis da 


\section{REVISTA APOENA - Per. dos Dis. de Fil. da UFPA}

Belém, 2019, V. 1, N.1.

natureza não são descobertas pela observação da natureza, mas são impostas pelo intelecto humano à natureza. "o mundo como o conhecemos é nossa interpretação dos fatos observáveis, à luz de teorias que inventamos" (POPPER, 1982, p. 218). Kant acentua o papel do sujeito investigador face à natureza. Popper, por sua vez, reformula as asserções kantianas afirmando que as leis da natureza são, sim, invenções nossas, contudo não são válidas $a$ priori, mas são geneticamente a priori. Nós tentamos impô-las à natureza, com grau variado de sucesso.

Popper não aceita a solução kantiana para o problema da indução, isto é, não admite que o princípio da indução - ou o princípio da causação - seja válido a priori. Não acha que a tentativa de proporcionar uma justificação a priori para os enunciados sintéticos seja válida. Para o filósofo, o problema da indução não tem solução. As várias dificuldades da lógica indutiva são intransponíveis. As inferências indutivas são injustificáveis. O método indutivo não é um procedimento válido para a ciência. Sendo assim, toda tentativa de validar a lógica indutiva conduz ou a uma regressão infinita ou à doutrina do apriorismo.

Assim sendo, Popper propõe a teoria do método dedutivo de prova como alternativa à indução. Isto é, a concepção segundo a qual uma hipótese só admite prova empírica após haver sido formulada, sua validação é a posteriori. Portanto, como procede o método de submeter criticamente à prova as teorias, e de selecioná-las conforme os resultados obtidos? "A partir de uma ideia nova, formulada conjecturalmente e ainda não justificada de algum modo (...) podem-se tirar conclusões por meio de dedução lógica" (POPPER, 2013, p. 31). Em seguida, essas conclusões são comparadas entre si e com outros enunciados pertinentes, com o intento de encontrar que relações lógicas existem no caso.

Finalmente, na perspectiva de Popper, as teorias são criações do nosso intelecto. $\mathrm{O}$ sujeito investigador tem um papel ativo face à natureza, questionando-a e tentando impor a ela as suas leis. No entanto, o cientista não deve tentar confirmar as suas teorias, mas sim refutálas. Pois a experiência não pode verificar hipóteses, apenas falseá-las, mediante testes empíricos. Sendo assim, testar uma teoria é sempre uma tentativa de provar a sua falsidade. Aquelas teorias que resistirem aos testes são corroboradas, isto é, aceitas provisoriamente como verdadeiras, mas ainda assim, estão sujeitas ao falseamento. 


\section{REFERÊNCIAS BIBLIOGRÁFICAS \\ REVISTA APOENA - Per. dos Dis. de Fil. da UFPA \\ Belém, 2019, V. 1, N.1.}

DIAS, Elizabeth de Assis. Popper: um Kantiano Não-Ortodoxo. Em Filosofia

Contemporânea: lógica, linguagem e ciência. São Paulo: ANPOF, 2013.

FERNANDES, Sergio. Foundations of objective knowledge. Dordrecht: Ed. Reidel, 1985.

KANT, Immanuel. Crítica da razão pura. Tradução de Fernando Costa Matos. Petrópolis, RJ: Ed. Vozes, 2013

_. Crítica da razão prática. Tradução de Afonso Bertagnoli. São Paulo: Brasil Editora, 2004.

_. Princípios metafísicos da ciência da natureza. Tradução de Artur Morão. Lisboa:

Edições 70, 1990.

_. Prolegómenos a toda metafísica futura. Tradução de Artur Mourão. Lisboa: Edições 70, 1988.

MILLER, David. Textos escolhidos. Tradução de Vera Ribeiro. Rio de Janeiro: Ed. PUC-Rio, 2010.

NEWTON, I. Principios Matemáticos de Filosofia Natural. São Paulo, Abril Cultural, 1979.

OLIVEIRA, P. E.; VALLE, B. Introdução ao pensamento de Karl Popper. Paraná:

Champagnat, 2010.

POPPER, Karl. Conjecturas e refutações. Tradução de Sérgio Bath. 5. Ed. Brasília: Editora Universidade de Brasília, 2008.

. Os dois problemas fundamentais da teoria do conhecimento. Tradução de Antônio Ianni Segatoo. São Paulo: Ed. Unesp, 2013.

_. A lógica da pesquisa científica. Tradução Leonidas Hegenberg e Octanny silvera de Mota. -2. Ed - São Paulo: Cultrix, 2013.

_. Conhecimento objetivo.Tradução de Milton Amado. São Paulo: Ed. Universidade de São Paulo, 1975

_.. Unended quest: an intellectual autobiography.Illinois: Open Court, 1990. 
REVISTA APOENA - Per. dos Dis. de Fil. da UFPA

Belém, 2019, V. 1, N.1.

_. O realismo e o objetivo da ciência.Lisboa: Dom quixote, 1987.

A vida é aprendizagem.Lisboa: Edições 70, 1999.

_. Em busca de um mundo melhor.Tradução Milton Camargo Mota. São Paulo: Martins, 2006.

A sociedade aberta e seus inimigos Vol. II. Tradução de Milton Amado. Belo Horizonte,

Ed. Itatiaia; São Paulo: Ed. da Universidade de São Paulo, 1974

TALIGA, Milos. Kant and Popper: Two Copernican Revolutions. In: Imannuel Kant and the Tradition of Critical Philosophy. 2004, Wisla. Disponível em:

<https://www.academia.edu/3057559/Kant_and_Popper_Two_Copernican_revolutions> Acesso em: Maio, 2015. 